Chapter 7

\title{
High Temporal Resolution Brain \\ Microdialysis as a Tool to Investigate \\ the Dynamics of Interactions Between \\ Olfactory Cortex and Amygdala in \\ Odor Fear Conditioning
}

\author{
Chloé Hegoburu, Luc Denoroy, \\ Anne-Marie Mouly and Sandrine Parrot \\ Additional information is available at the end of the chapter \\ http://dx.doi.org/10.5772/57490
}

\section{Introduction}

Fear conditioning is one of the most widely used paradigms for studying the neurobiology of emotional learning. In this paradigm, an emotionally neutral stimulus (the conditioned stimulus or CS) is paired with an aversive unconditioned stimulus (US), generally a mild foot shock. After a few trials, re-exposure to the CS alone elicits a fear response, proceeding through the necessary connecting structures, and ending with the autonomic and motoric effector outputs. This fear response is part of an anticipatory response to danger [1], initiating a range of defensive reactions that counter threats to survival [2]. The most universal response is a postural immobility, called freezing [3, 4]. Moreover, the threatening stimulus also triggers the activation of the hypothalamic subnuclei to induce an increase in blood pressure, ultrasonic vocalizations emission, or the release of stress hormones.

The vast majority of studies devoted to investigate the neural basis of fear conditioning have used auditory cues as conditioned stimuli and the neural pathways involved in auditory fear conditioning have been well characterized [5-8]. The information carried by the auditory CS can take one of two pathways: either directly from the thalamus to quickly reach the amygdala or the CS can travel from the auditory thalamus to the auditory cortex before reaching the amygdala. These thalamic and cortical areas send projections to the lateral nucleus of the amygdala, which is a site of CS-US convergence. The lateral nucleus, in turn, projects to the 
central amygdala, which controls the expression of fear responses by way of projections to brainstem areas. The major conclusion of these studies is that the amygdala plays a critical role in linking external stimuli to defense responses through synaptic plasticity. However, although the amygdala seems to be essential to the formation and storage of fear memories, it might not store all aspects of the aversive event. Indeed, plasticity also occurs in cortical areas during fear conditioning, which could support declarative memories of the learning episode mainly through interactions with the medial temporal lobe memory system [9-13]. Thus, the amygdala may store some aspects of fear memory and facilitate the storage of other, more sensoryrelated, aspects of fear memory in cortical areas [14]. Yet few studies have investigated this question [15].

Intriguingly, whereas olfaction plays a dominant role in rat behavior from birth throughout adulthood, very few studies have used odor cues as CS in fear conditioning paradigms. Yet, odors have a rather unique status for eliciting emotional memories.[16]. This particularity might be linked to the uniqueness of the anatomy of the olfactory system. Indeed, in contrast to the other sensory pathways, olfactory information has a direct access to the amygdala and olfactory (piriform) cortex with no obligatory thalamic relay [17-19]. The literature suggests that, similarly to what is observed in auditory fear conditioning, the amygdala is a key brain structure involved in the acquisition, consolidation and expression of odor fear conditioning [20-26]. Recently, some studies also suggest that the posterior piriform cortex (PPC) may play a critical role in this associative learning $[23,26,27]$. Therefore, the olfactory system constitutes a particularly relevant model for studying the relative contribution of sensory cortices and amygdalar nuclei to odor fear learning.

For several years now, the glutamatergic transmission in the amygdala is known to play a critical role in the acquisition of fear conditioning [28, 29]. Indeed, pharmacological studies show that NMDA and AMPA subclasses of glutamate receptors are crucial for synaptic plasticity and long-term potentiation to occur in the amygdala, sustaining the formation of the CS-US association [25, 30-35]. In addition, the GABAergic transmission seems to be also involved in the acquisition of fear learning. Intra-amygdala infusion of the $\mathrm{GABA}_{\mathrm{A}}$ receptor agonist muscimol before training impairs learning [36, 37]. Therefore, glutamate and GABA neurotransmission are thought to play a critical role in the acquisition and expression of fear memories (for review, see [38]).

Beside these neuropharmacological studies, a few neurochemical studies have directly measured glutamate or GABA levels in the amygdala during auditory fear conditioning, using a 10 -min sampling rate $[39,40]$. However, this sampling rate is too long as compared to the rapid neurobiological events underlying fear conditioning. An approach allowing rapid, subminute sampling is required to better characterize the dynamics of neurotransmitter changes evoked by the stimuli involved in fear conditioning experiments [41]. Until now, the precise time course of the differential involvement of the amygdala and sensory cortices in fear conditioning has received little investigation. The aim of this chapter is to show that intracerebral in vivo microdialysis with high temporal resolution is an interesting tool to investigate the time course of activation of amygdala and sensory cortices in this learning. 


\section{Monitoring neurotransmitters using microdialysis}

\subsection{Principle of the technique and analytical considerations}

Microdialysis has become a conventional technique for sampling low molecular weight molecules present in the extracellular medium of many organs from animals or humans [42]. In the brain, it has been used in vivo or ex vivo to monitor amino acids neurotransmitters as excitatory or inhibitory amino acids as glutamate and GABA, monoamines as dopamine, noradrenaline, serotonin and/or neuropeptides for instance. The microdialysis relies on a semipermeable membrane that allows free diffusion of solutes between the extracellular space and an artificial fluid. A microdialysis probe consists of two concentric tubes with the distal part (1-5 mm) covered by a dialysis hollow fibre whose cut-off ranges between 6,000 and 100,000 Da. Such a probe is inserted into a living brain tissue and is perfused by an isotonic physiological fluid. Molecules diffuse down their concentration gradient across the dialysis membrane in a bidirectional way ("dialysis" for collecting endogenous molecules or "reverse dialysis" for applying exogenous compounds) (Figure 1). In the case of collection, the relative recovery across the probe membrane, defined as the ratio between the extracellular concentration and the concentration of a compound in the dialysate collected at the outlet of the probe, depends on several factors: it increases with the surface of the membrane, it decreases with higher flow rate of the perfusion fluid, and it varies with the chemical and physical characteristics of the membrane [43]. The choice of the dialysis membrane can be crucial for compounds present at trace concentration or when the limit of detection of the analytical method is relatively moderate. For instance, a short length (i.e. 1-2 $\mathrm{mm}$ ) of the membrane chosen to sample a very small brain area in rats, such as the periaqueductal grey matter, the locus coeruleus, the amygdala and hypothalamic nuclei leads to a low recovery of sampling, making difficult the monitoring of low concentrated compounds as monoamines or neuropeptides. Depending on the methodological parameters, recovery values usually reported in literature are between 5 and $25 \%$ for amino acids or monoamines and can reach $<1 \%$ for neuropeptides. Another point to take into account is the choice of the geometry of the probe tubings when considering the sampling rate, especially when designing in vivo microdialysis on awake animals. These latter peculiar points will be explained and detailed in the next section part of the manuscript.

As the microdialysis probe is continuously perfused at a constant flow rate, continuous sampling of neurotransmitters is possible with no loss. Indeed, neurotransmitters present in the microdialysate can be directly analyzed without clean-up procedures as high molecular weight proteins cannot cross the dialysis membrane thanks to the cut-off of the membrane used. However, manipulation of microdialysis samples requires precaution in case of amino acids: use of sterile tubes, filtered aCSF and wear of gloves avoiding contamination due to the ubiquitous presence of free amino acids on labware and skin. Eventually, samples may be usually analyzed by a separative method like high performance liquid chromatography (HPLC) or capillary electrophoresis (CE) [44, 45]. Microdialysates can be analyzed on-line, i.e., at the outlet of the probe, through an analytical interface, or off-line i.e., after sample collection in micro-tubes, in combination with a separative method [44, 46, 47]. Thus, the determination 


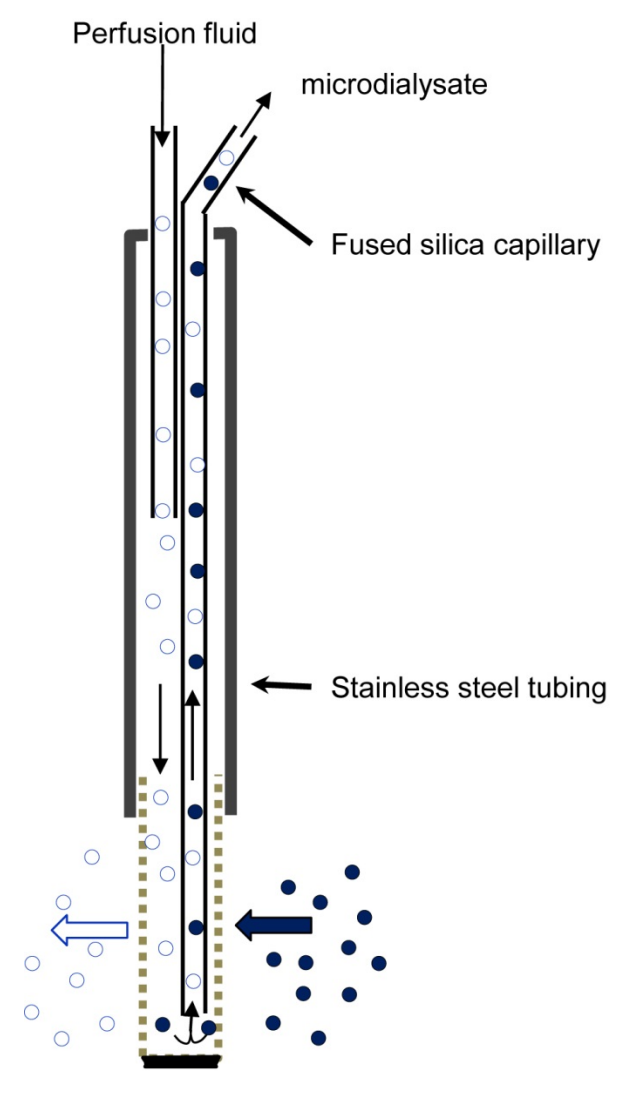

\section{..... Dialysis membrane}

Figure 1. Schematic representation of a microdialysis probe. The probe is continuously perfused by an isotonic physiological fluid. Endogenous compounds (filled circles) diffuse through the dialysis membrane (filled arrow) and are sampled in the microdialysate collected at the outlet of the probe. Drugs (open circles) can be added to the perfusion medium and can diffuse out of the probe into the extracellular medium (open arrow) providing a means of local administration. From [109], with permission from John Wiley and Sons.

of concentrations in each sample reflects the average concentration over the defined sampling duration. Data are classically expressed as \% of the average of the first samples collected, corresponding to baseline. As a consequence, microdialysis (except in very peculiar methodological contexts not explained in this chapter) is considered as a semi-quantitative method as it permits to monitor precisely relative variations of neurotransmitters.

Analysis of microdialysates has commonly used HPLC with electrochemical [48, 49] or fluorometric detection [50,51], and also enzymatic methods [52]. However, these analytical techniques exhibit poor mass sensitivity and require large volume samples to determine 
neurotransmitter contents. As a consequence, despite constant improvements in HPLC [50, 51, 53], the required sample volume may still be too large, leading to lengthy dialysis sampling times and poor temporal resolution. Consequently, most microdialysis experiments were severely limited by the temporal resolution of microdialysis (5-30 min) compared to rapid changes occurring in the extracellular concentrations of neurotransmitters. In contrast, microdialysis coupled to $\mathrm{CE}$, a more recent technique, allows the monitoring of rapid changes in the extracellular concentration of neurotransmitters by analysing nanovolume dialysates with low limits of detection. At present, it appears to be suitable for microdialysis with high sampling rate. Often coupled to laser-induced fluorescence (LIF) detection or mass spectrometry (MS), capillary electrophoresis has become one of the most powerful analytical tools for the routine determination of neurotransmitters because it offers the advantage of rapidity, high resolution and sensitivity, while requiring very small sample sizes [44, 54, 55]. In brain microdialysates, glutamate and GABA [56-64] were often analysed using CE with LIF detection. However, as amino acid neurotransmitters are not fluorescent at wavelengths of most commercially available lasers, derivatization prior to the separation is needed. Fluorescent reagents, as naphthalene-2,3-dicarboxaldehyde (NDA), orthophtaldehyde (OPA) or fluorescein isothiocyanate, reacting with the primary amine function of neurotransmitters, allow their detection following laser excitation at 442, 325, or $488 \mathrm{~nm}$, respectively [63-65]. Several groups, including our own, have developed methodologies for the CE-LIF analysis of brain microdialysates after a derivatization of samples with fluorogenic agents, even on sub-microliter dialysates obtained with high temporal resolution microdialysis (5s - $1 \mathrm{~min}$, [44] for minireview).

\subsection{Set-up for high temporal microdialysis on behaving animal}

According to the neurophysiological question asked, the experimental set-up for microdialysis experiments has to be carefully designed: the choice of microdialysis probe according to the targeted brain area, the choice of the analytical method to quantify dialysate neurotransmitters and the coupling of the experimental set-ups or approaches are all crucial to succeed in neurochemical studies. The aim of the study described here [66] was to monitor amino acid neurotransmitters as glutamate and GABA in brain areas involved in emotional learning and memory using odor fear conditioning. Indeed, while a few studies have investigated the time course of events separately in the auditory cortex and the amygdala during auditory fear conditioning [11, 12], no study up to date has been conducted to investigate simultaneously the changes in amygdala and sensory cortical areas in the same animal during fear conditioning.

Our group previously reported lasting changes in electrophysiological field potential signals in both posterior piriform cortex (PPC) and amygdala (basolateral nucleus, BLA) after a session of odor fear conditioning [23]. As a consequence, we conducted an experiment using a dualmicrodialysis probe implantation, in order to compare the time courses of changes in GABA and glutamate concentrations, monitored simultaneously in BLA and PPC during odor fear conditioning. Very few groups have developed dual (or triple) implantation of microdialysis probes on the same animal $[67,68]$. Indeed in most studies using brain microdialysis, dialysates collection is usually performed in one brain structure at a time, sometimes on different days. Literature on microdialysis experiments in BLA is rather abundant, mainly for monoamines. 
There are only a few papers in the literature reporting microdialysis studies in the piriform cortex in an epileptic model [69] or during a feeding/diet procedure [70]. Two other studies were devoted to glutamate monitoring at 20 or 30-min sampling rate in anesthetized [71] or awake rats [72]. In order to target the centre of each brain structure and avoid excluding rats with inaccurate implantation on one hand, and in order to optimize the amount of collected glutamate and GABA in the microdialysates for analytical quantification on the other hand, 1.5-mm microdialysis probes were used for both BLA and PPC. However, due to the size of the probes and the vicinity of amygdala and olfactory cortex, we implanted one probe per hemisphere, BLA probe on one side, PPC probe contralaterally (Figure 2). As the acquisition session of odor fear conditioning was short-lasting (30 min), we monitored glutamate and GABA at high sampling rate using CE-LIFD as analytical technique. When performing high sampling rate, it is crucial to optimize the geometry of the probe tubings.

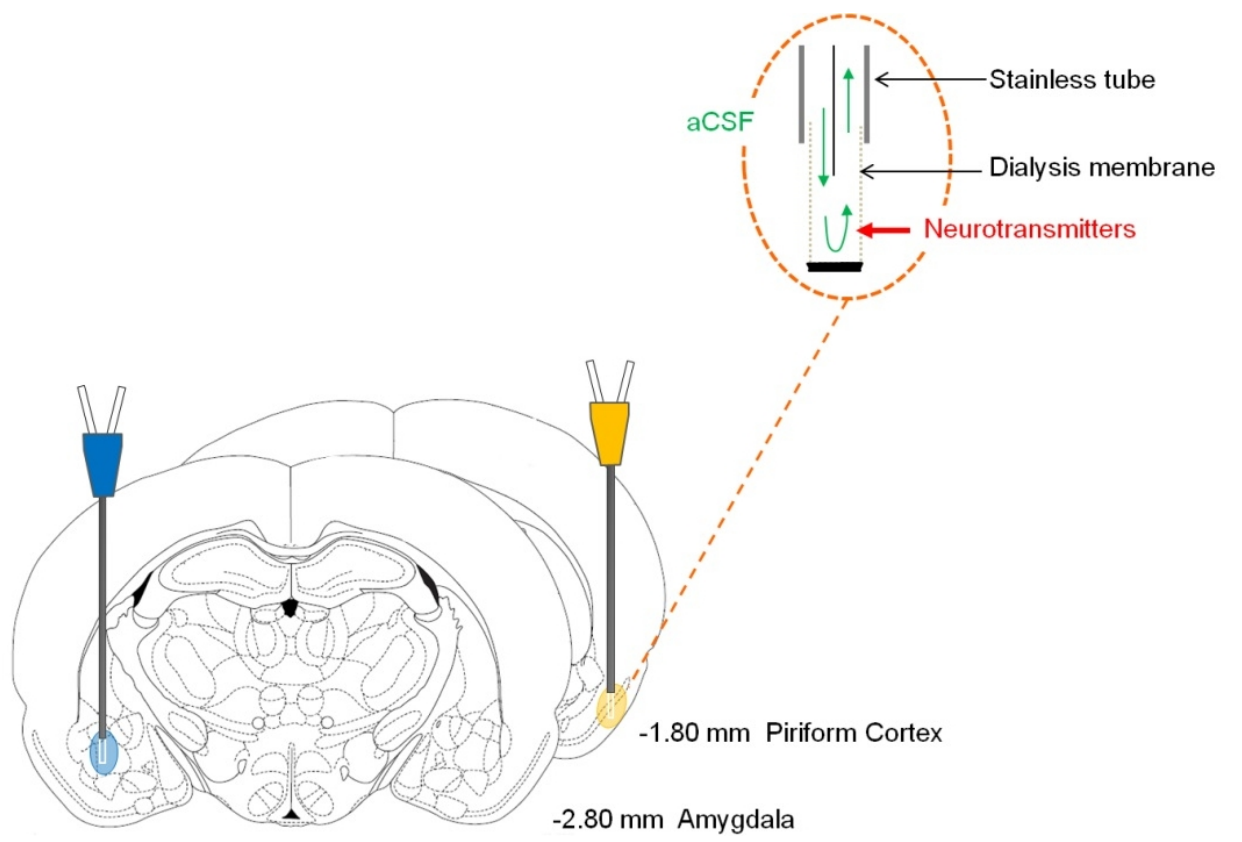

Figure 2. Brain sections from Paxinos \& Watson's atlas with a schematic probe implanted in the left basolateral amygdala and the other implanted in the right posterior piriform cortex of the same freely-moving rat for simultaneous glutamate and GABA monitoring.

Indeed, a high sampling rate requires appropriate probe tubings since solutes could undergo more longitudinal diffusion in the outlet probe tubing if the interval of time between dialysis and collection, also called 'dead time, is superior to the sampling time [56]. As a consequence, to avoid mixing of analytes between successive samples, the dead volume of these tubings has to be minimized. This is particularly relevant when microdialysis experiments are carried out on awake animals because the setting requires long inlet and outlet probe tubings in order to let the animals move freely. In our odor fear conditioning, the set-up includes specific 
characteristics: an experimental chamber with a grid for electrical stimulation which is a mild footshock (Unconditioned Stimulus, US) and with an ventilation system bringing and removing the odor (Conditioned Stimulus, CS); besides, this experimental chamber has to be placed in a soundproof box in which we can position cameras to record the behavior of the animal. Material for microdialysis (perfusion pump) and collection have to be placed outside the box for not disturbing the animal in learning. In our set-up, the height of the box reaches almost one meter (Figure 3). The dead volume can be greatly minimized by using capillary tubings with sub-50 $\mu \mathrm{m}$ inner diameters, as previously demonstrated by our group [56]. By using a $40-\mu \mathrm{m}$ inner diameter, we have optimized the microdialysis set-up for odor conditioning by adapting methods that our group previously used for an accurate monitoring of 30s pharmacologically-induced increases [73] or 20-s behaviourally-induced variations [56] in extracellular levels of amino acids neurotransmitters. We showed that the experimental determination of the dead time is necessary in order to adapt each set-up to the sampling rate required (Figure 4). The final length of the outlet tubing is $120 \mathrm{~cm}$ with a dead time of $1 \mathrm{~min}$ 30 at $2 \mu \mathrm{L} / \mathrm{min}$ as sampling rate and the final sampling resolution is $1 \mathrm{~min}$. The time scale in the figures corresponds to the real time of collection of the fractions. Administration of odor was timed to take into account the outlet dead time of the dialysate system.

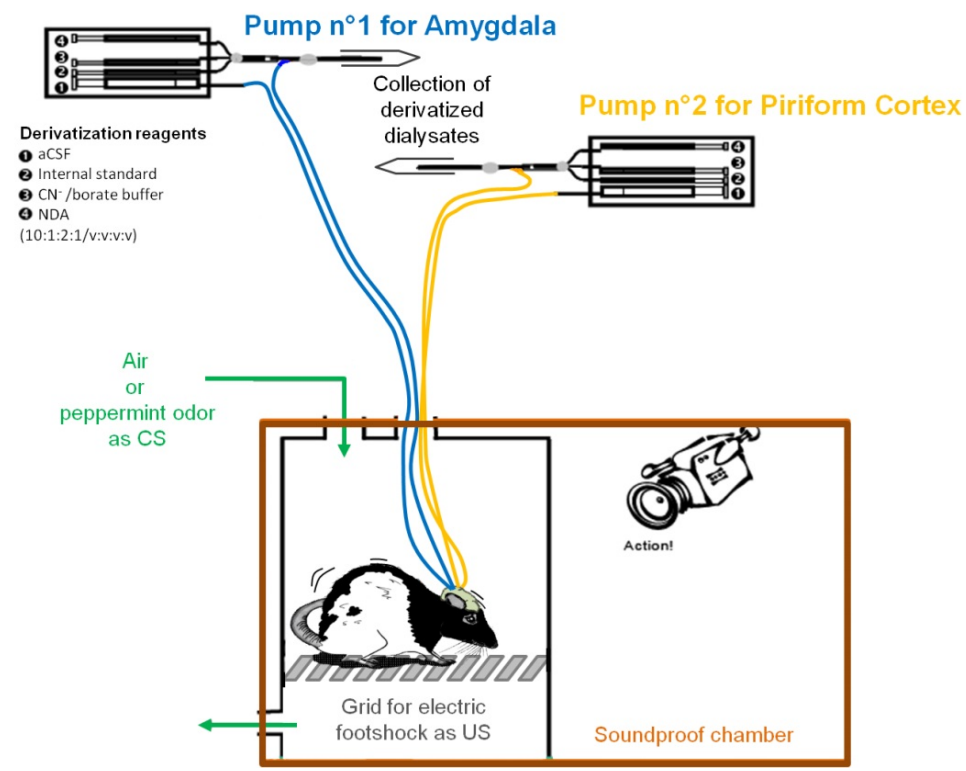

Figure 3. Experimental set-up for both microdialysis sampling and dialysates derivatization during the acquisition of odor fear conditioning. The dual probe-implanted animal is placed in an experimental chamber for odor (conditional stimulus) and shock (unconditional stimulus) deliveries, required in the learning procedure. This chamber is soundproof in order to prevent external noise to interfere with the animal's behaviour. Microdialysis and derivatization are performed simultaneously using one pump per brain area and four syringes delivering artificial cerebrospinal fluid (aCSF) in the inlet of the probe or reagents (NDA as derivatization agent in presence of cyanide ions at pH 8.7 and internal standard for better quantification by capillary electrophoresis with laser-induced fluorescence detection) to tag the neurotransmitters at the outlet of the probe. 
Another analytical constraint is to tag the sample in order to detect the amino acids collected during the dialysis experiment. As glutamate and GABA are not fluorescent, we employed a validated home-made on-line system able to deliver the derivatization reagents directly in the collection tube [56], allowing to derivatize the dialysate while dialyzing, without sample loss, noticeable dilution or contamination and without increasing the dead volume of the probe. Thus, the collection tube is not only the micro-reactor of derivatization, but also the injection tube for capillary electrophoresis analysis (Figure 3).

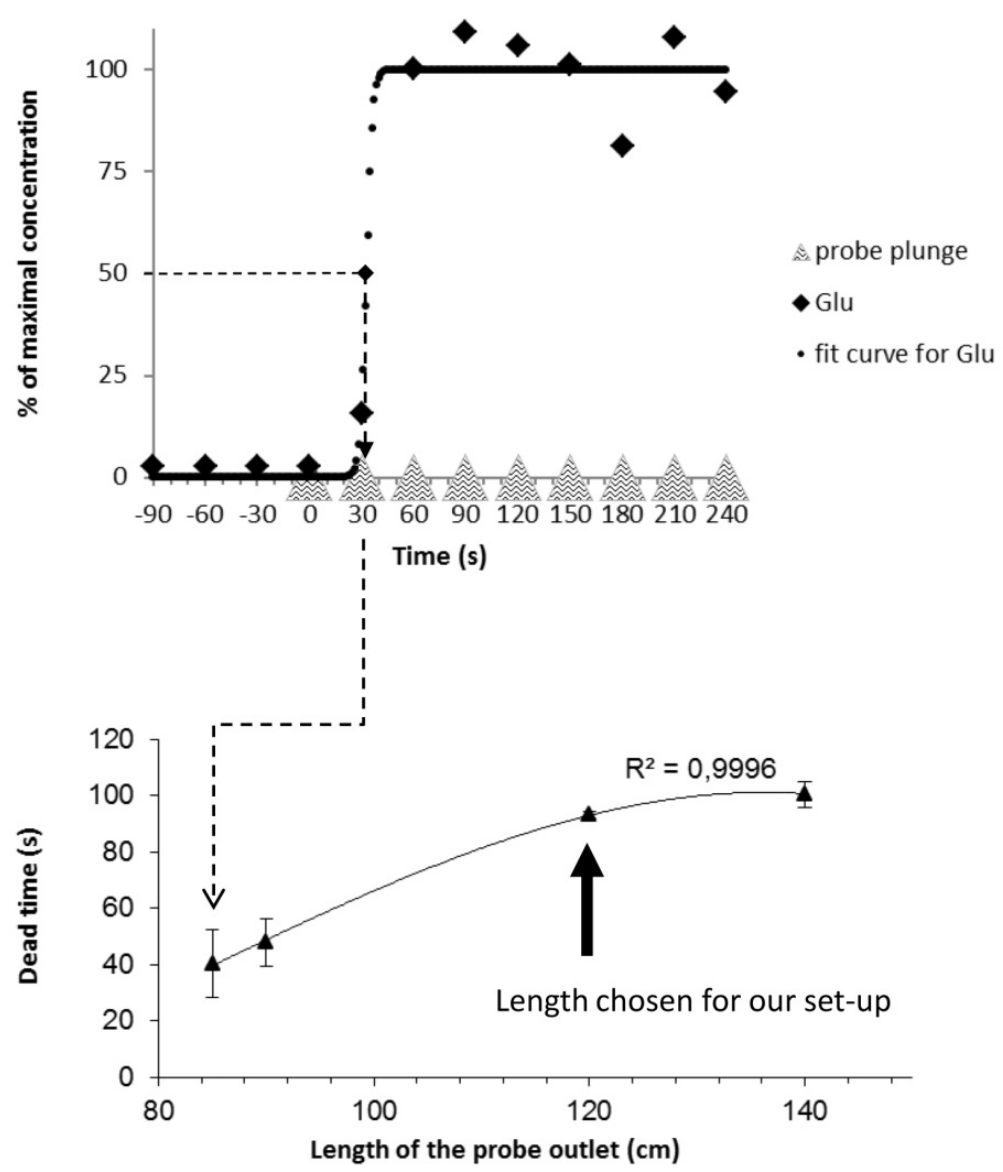

Figure 4. Example of determination of the dead time of an $85-\mathrm{cm}$ outlet home-made probe perfused at $2 \mu \mathrm{L} / \mathrm{min}$ by plunging the probe into a known concentration of glutamate at $\mathrm{t}=0 \mathrm{~s}$. The dead time is determined as the time when $50 \%$ of the maximal response is reached using a sigmoid curve fitting the 30 -s glutamate monitoring (up). By varying the length of the outlet tubing of customized probes $(n=3)$, the dead time of probes can be interpolated and the final length of outlet tubing (here, $120 \mathrm{~cm}$ for a dead time of $1 \mathrm{~min} 30 \mathrm{~s}$ ) can be chosen according to the height of our experimental set-up and the 1-min sampling rate (bottom). As a consequence, administration of odor was timed to take into account the outlet dead volume of the dialysate system. 
Figure 5 presents an example of typical electropherogramm obtained from 1 minute sampling rate of brain microdialysate in freely-moving rat during the acquisition of fear conditioning. Note that the concentrations for GABA and glutamate are similar in PPC or in BLA.

\section{Posterior \\ Piriform \\ Cortex}

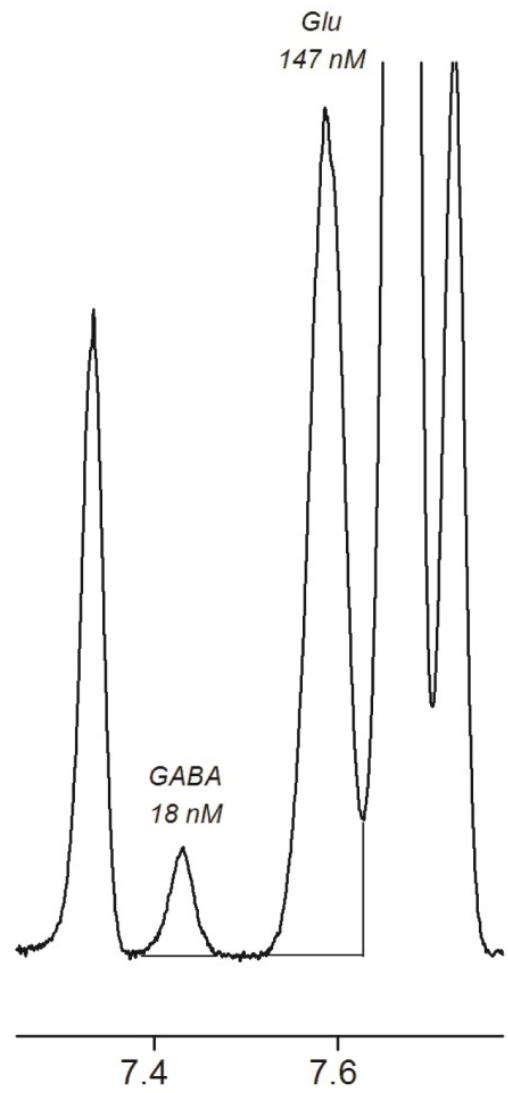

Migration time (min)
Basolateral

Amygdala

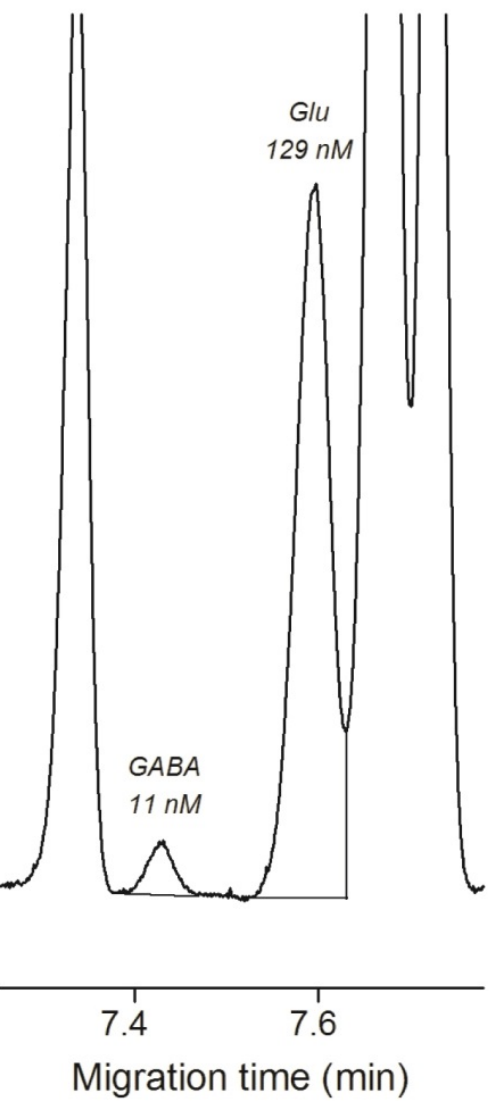

Figure 5. Typical electropherograms from microdialysates obtained in posterior piriform cortex and basolateral amygdala on the same freely-moving Long-Evans rat. Samples were collected every minute at $2 \mu \mathrm{L} / \mathrm{min}$ and derivatized online as described in Figure 3 of this chapter. Adapted from [110]. 


\section{Neurochemistry of odor fear conditioning}

\subsection{Interactions between amygdala and piriform cortex in odor fear conditioning}

The odor fear conditioning paradigm consisted of six 20-s odor/ 2-s shock associations presented with an interval of 4 minutes between each pairing. In the amygdala, the first odorshock association is accompanied by a significant but transient $+40 \%$-increase of glutamate release. During the next trials, the concentrations returned to the baseline levels or slightly below. In contrast, in piriform cortex, each odor-shock association is followed by a transient $+25 \%$-increase in glutamate release. The comparison of the pattern of release observed in the two structures has also shown that the increase in the amygdala during the first association occurred 1-2 min before the first response in the piriform cortex (Figure 6).

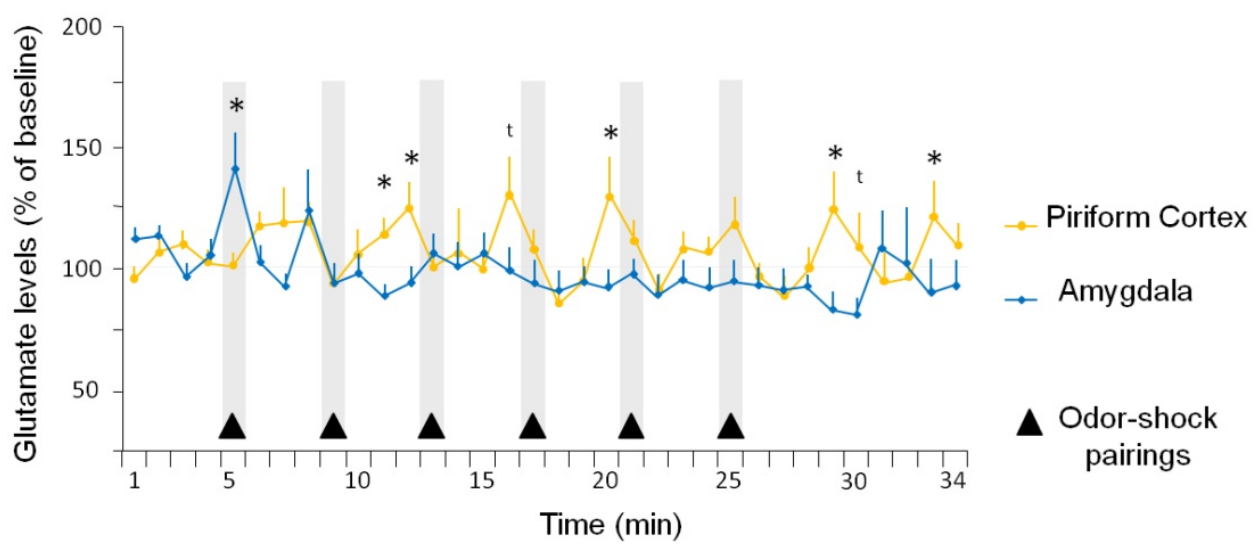

Figure 6. Comparison of glutamate concentration fluctuations in the amygdala and the piriform cortex during odor fear acquisition session. Glutamate concentrations were measured throughout the session and expressed as a percentage of baseline calculated as the mean of concentration for the four points preceding the first pairing. Black arrowheads above the $x$-axis symbolize trial occurrence. Light gray vertical bars indicate the timing of the 4-min intertrial intervals. $\left.{ }^{*}\right)$ Significant difference between the two structures $(p<0.05)$; $(\#)$ tendency toward significant difference ( $p$ $<0.09)$. Adapted from [66].

The profile of GABA variations during odor fear conditioning was similar in duration and amplitude to that obtained for glutamate presented in Figure 6, i.e. with an enhancement of GABA levels in the amygdala during the first pairing and increases of GABA concentrations in piriform cortex 1-2 min after each pairing. As glutamate and GABA fluctuations were not overall significantly different throughout the experiment, it can be suggested that GABA increases could be induced by glutamate increases, as shown by $[74,75]$ in the prefrontal cortex.

The high temporal resolution microdialysis allowed us to highlight a differential dynamics of neurotransmitters release in the piriform cortex and amygdala during odor fear acquisition. Taken together, these results suggest that there is a temporal sequence of neurochemical events in the amygdala and piriform cortex, a very precise dynamics of neurotransmitters during the 
early stages of the acquisition session, which could be involved in the initiation of plastic changes supporting the formation of the memory.

\subsection{Functional significance of neurochemical data}

Glutamate collected from the BLA and PPC may have originated from both extrinsic and intrinsic sources. Indeed, the BLA receives afferences from primary olfactory cortex [76-78] and from other associative areas [19,79], providing an extrinsic source of glutamate. Similarly, PPC receives a strong glutamatergic input from the olfactory bulb as well as inputs from the BLA, prefrontal cortex, and hippocampus [80-82]. In addition, both the BLA and PPC contain glutamatergic pyramidal cells that send axon collaterals to neighboring cells, thus providing an intrinsic source of glutamate $[79,83,84]$. Concerning GABA origin, in both BLA and PPC, GABA is released by local inhibitory interneurons $[79,85]$.

While in vivo microdialysis is a useful method for monitoring the neurotransmitters present in the brain extracellular fluid [86], many studies have questioned to what extent dialysate glutamate concentration reflects the amount of glutamate released by the presynaptic neuron. Indeed, due to the ubiquitous localization of its metabolism enzymes and transporters in all brain cells and its paramount role in protein synthesis and general metabolism, numerous works attempted to determine the origin of extracellular glutamate. If the proportion of extracellular glutamate taken up by astrocytes is about $80-90 \%$ of the whole glutamate pool [87], the part of the neuronal glutamate, i.e. released for the only neurotransmission purpose, is still matter of debate, because glutamate may come from many sources of effluxes as neuronal "classical" release [88], exchange via cysteine/glutamate transporters [89-92], inversion of transporters [93] and glial release via exocytosis or non-exocytosis [94-96]. Former methodological strategies used for monoamine neurotransmitters to impair the vesicular neuronal release by lowering or removing calcium in aCSF or by blocking nerve impulse $\mathrm{Na}$ ${ }^{+}$-dependent channels with tetrodotoxine (TTX) gave contradictory answers: some studies reported decreases in basal level of glutamate in dialysate, which is in favour of the neuronal origin of basal extracellular glutamate. In contrast, other studies described no change or even increases under such experimental conditions [97]. Consequently, it was suggested that most part of neurotransmitter glutamate released into synaptic cleft in basal conditions may be taken up into surrounding glia and diffuses poorly to the dialysis probe. The same question can be asked for extracellular GABA because its metabolism is tightly linked to glutamate. As for glutamate, unsuccessful conclusions were also reported regarding the origin of dialysate GABA in basal conditions [97]. However, increasing the microdialysis sampling rate had been proposed in order to observe the rapid variations in glutamate extracellular level which are expected to occur in neurophysiological events $[73,98]$. Recent studies using high sampling rate microdialysis showed that NMDA application [99] or electrical stimulation of the prefrontal cortex [100] increases dialysate glutamate concentrations in brain regions receiving projections from this area and that the increase is suppressed or partly altered by TTX [99, 100]. These studies strongly suggest that the transient increase in dialysate glutamate detected under these conditions really represents evoked neurotransmitter glutamate release [101]. 
Extracellular (or dialysate) concentrations of glutamate and GABA may not always provide a reliable index of their synaptic exocytotic release. Indeed, a strict compartment between intrasynaptic and extra-synaptic was evidenced with poor spill-over from synaptic compartment to extra-synaptic part [102, 103], mainly due to a strong glial uptake. So that, the changes in extracellular concentrations of glutamate and GABA under specific pharmacological and behavioural stimuli should not be only interpreted as a consequence of the activation of specific neurochemical circuits, but as an expression of the activity of the neuron-astrocyte unit in specific circuits of the brain. Several authors proposed that dialysate changes in glutamate and GABA could be used as an index of volume transmission mediated actions of these two neurotransmitters. This hypothesis is based firstly on the assumption that the activity of neurons is functionally linked to the activity of astrocytes, which can release glutamate and GABA to the extracellular space [94, 104]; secondly, on the existence of extrasynaptic glutamate and GABA receptors with functional properties different from those of receptors located in the synapse [105, 106]; and thirdly, on the experimental evidence reporting specific electrophysiological and neurochemical effects of glutamate and GABA when their levels are increased in the extracellular space [107]. Thus, glutamate and GABA, once released into the extracellular compartment, can diffuse and have long-lasting effects modulating glutamatergic and/or GABAergic neuron-astrocytic networks and interact with neurons containing other neurotransmitters and located in the same areas of the brain. In conclusion, monitoring of glutamate and GABA concentrations in the extracellular space using microdialysis may provide an indirect index of amino acids synaptic neurotransmission while giving direct indications of amino acids volume neurotransmission [101].

A few studies have specifically measured extracellular glutamate or GABA in brain structures involved in fear conditioning, investigating the neurotransmitters changes in amygdala during auditory fear learning. More precisely, these microdialysis studies have described a longlasting decrease in GABA during expression of conditioned fear [39] and a small increase in glutamate during auditory fear conditioning [40]. However, these studies suffer from poor (10-20 $\mathrm{min}$ ) temporal resolution associated with traditional microdialysis. Only one study has used high temporal resolution microdialysis to measured glutamate and GABA into the amygdala during the acquisition of auditory fear conditioning [108] and suggests that the covariations of glutamate and GABA may be explained as a glutamate-induced increase in GABA. This study also showed an increase in neurotransmitters levels in the amygdala only for the first association after which the concentration returned to baseline levels. This last result is in agreement with our microdialysis data for the amygdala in odor fear conditioning. Unfortunately, microdialysis was not performed in the auditory cortex, thus precluding any comparison with our own data on the piriform cortex. Nevertheless, there are some electrophysiological data which show that the amygdala is activated before the auditory cortex in auditory fear learning $[9,11]$. These data are in accordance with our findings and confirm the differential activation of the amygdala and sensory cortices within the acquisition session of fear conditioning. 


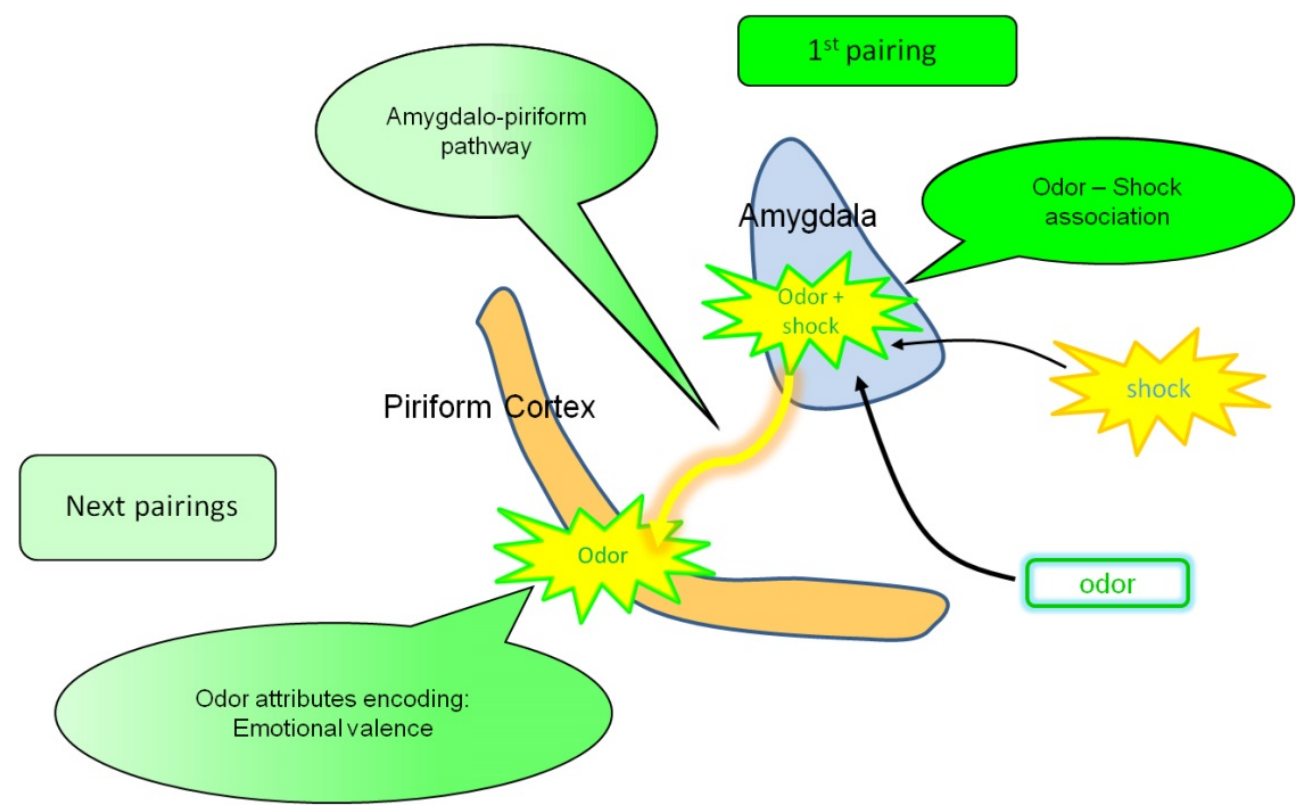

Figure 7. Functional hypotheses on the interactions between the amygdala and the piriform cortex during the acquisition of odor fear learning. An early transient response in the amygdala may allow fast signaling following the first CSUS pairing. Projections from the amygdala to the piriform cortex may provide a pathway through which the amygdala can modulate cortical processing of olfactory information and initiate the storage of the various attributes of the learned odor. The piriform cortex might store certain aspects of the conditioning experience, including the learned hedonic value of the CS odor.

Our microdialysis data led us to formulate the following working hypothesis (Figure 7). During the first pairing, the amygdala glutamatergic transmission would allow the formation of the memory of the CS-US association as it is the case for auditory fear conditioning. The new idea brought by our data is that this could be initiated by a single trial, since no further increase in glutamate was detected in the amygdala for the next pairings. In parallel, the amygdala would trigger the first glutamate increase detected in the olfactory cortex. This would be achieved through the involvement of a direct projection pathway between the amygdala and the piriform cortex [82]. After that, the piriform cortex would progressively build the memory of the different attributes of the learned odor across the next trials.

What are the strengths of our data? This work was aimed at studying the neurochemical interaction between the amygdala and the piriform cortex in odor fear conditioning. We described a differential activation dynamics between the amygdala and the olfactory cortex within the acquisition session. This dynamic reveals an early and transient involvement of the amygdala, restricted to the first odor-shock association followed by the activation of the olfactory cortex 
during the next associations, which persists until the end of the acquisition session. Until now, most studies questioning the role of the amygdala and sensory areas in fear conditioning have used local lesions or inactivation before or after the acquisition session. Our technical approach is one of the very few allowing online monitoring of neurochemical events occurring in parallel in the amygdala and olfactory cortex, using a temporal resolution compatible with the observation of very transient changes.

\section{Conclusion and perspectives}

The recent development of high sampling rate microdialysis coupled with high-performance separative microtechniques able to handle sub-microliter sample allows monitoring rapid changes in extracellular levels of amino acid neurotransmitters. Such a platform allows in vivo investigating neurotransmission in freely-moving animals learning fear as in odor fear conditioning. Using two microdialysis probes, we were able to study the neurochemical interactions between two major brain areas involved in the acquisition and consolidation of odor fear conditioning: the amygdala which role is crucial for the formation of fear memory and the piriform cortex which could encode other aspects of the aversive event. Our data suggest that projections from the amygdala to the piriform cortex might provide a pathway via which the amygdala could modulate the cortical processing of olfactory information and initiate the progressive storage of the different attributes of the learned odor in long-term memory.

\section{Author details}

Chloé Hegoburu ${ }^{1,2,4}$, Luc Denoroy ${ }^{3,4}$, Anne-Marie Mouly ${ }^{2,4}$ and Sandrine Parrot ${ }^{4,5}$

*Address all correspondence to: sandrine.parrot@univ-lyon1.fr

1 Present address: Center for Psychiatric Neuroscience, Prilly, University of Lausanne, Lausanne, Switzerland

2 CNRS, UMR 5292, Lyon Neuroscience Research Center, Olfaction: From Coding to Memory Team, Lyon, France

3 University Lyon, Lyon Neuroscience Research Center, BioRaN team, Lyon, France

4 University Lyon, Lyon, France

5 INSERM, U1028, Lyon Neuroscience Research Center, NeuroDialyTics, Lyon, France 


\section{References}

[1] Bevins RA, Ayres JJB. One-trial context fear conditioning as a function of the interstimulus interval. Animal Learning \& Behavior. 1995;23 (4):400-10.

[2] Davis M, Shi C. The amygdala. Current biology : CB. 2000;10(4):R131.

[3] Blanchard RJ, Blanchard DC. Crouching as an index of fear. J Comp Physiol Psychol. 1969;67(3):370-5.

[4] Blanchard DC, Blanchard RJ. Innate and conditioned reactions to threat in rats with amygdaloid lesions. J Comp Physiol Psychol. 1972;81(2):281-90. Epub 1972/11/01.

[5] LeDoux JE. Emotion circuits in the brain. Annu Rev Neurosci. 2000;23:155-84. Epub 2000/06/09.

[6] Maren S. Neurobiology of Pavlovian fear conditioning. Annu Rev Neurosci. 2001;24:897-931. Epub 2001/08/25.

[7] Maren S, Quirk GJ. Neuronal signalling of fear memory. Nat Rev Neurosci. 2004;5(11):844-52. Epub 2004/10/22.

[8] Myers KM, Davis M. Mechanisms of fear extinction. Molecular psychiatry. 2007;12(2):120-50. Epub 2006/12/13.

[9] Edeline JM, Pham P, Weinberger NM. Rapid development of learning-induced receptive field plasticity in the auditory cortex. Behav Neurosci. 1993;107(4):539-51. Epub 1993/08/01.

[10] McClelland JL, McNaughton BL, O'Reilly RC. Why there are complementary learning systems in the hippocampus and neocortex: insights from the successes and failures of connectionist models of learning and memory. Psychol Rev. 1995;102(3): 419-57. Epub 1995/07/01.

[11] Quirk GJ, Armony JL, LeDoux JE. Fear conditioning enhances different temporal components of tone-evoked spike trains in auditory cortex and lateral amygdala. Neuron. 1997;19(3):613-24. Epub 1997/10/23.

[12] Armony JL, Quirk GJ, LeDoux JE. Differential effects of amygdala lesions on early and late plastic components of auditory cortex spike trains during fear conditioning. J Neurosci. 1998;18(7):2592-601. Epub 1998/04/16.

[13] Weinberger NM. Specific long-term memory traces in primary auditory cortex. Nat Rev Neurosci. 2004;5(4):279-90. Epub 2004/03/23.

[14] Maren S. Building and burying fear memories in the brain. Neuroscientist. 2005;11(1):89-99. Epub 2005/01/06.

[15] Sacco T, Sacchetti B. Role of secondary sensory cortices in emotional memory storage and retrieval in rats. Science. 2010;329(5992):649-56. Epub 2010/08/07. 
[16] Chu S, Downes JJ. Odour-evoked autobiographical memories: psychological investigations of proustian phenomena. Chem Senses. 2000;25(1):111-6. Epub 2000/02/11.

[17] Price JL. An autoradiographic study of complementary laminar patterns of termination of afferent fibers to the olfactory cortex. J Comp Neurol. 1973;150(1):87-108. Epub 1973/07/01.

[18] Savander V, LeDoux JE, Pitkanen A. Topographic projections from the periamygdaloid cortex to select subregions of the lateral nucleus of the amygdala in the rat. Neurosci Lett. 1996;211(3):167-70. Epub 1996/06/28.

[19] McDonald AJ. Cortical pathways to the mammalian amygdala. Prog Neurobiol. 1998;55(3):257-332. Epub 1998/06/27.

[20] Cousens G, Otto T. Both pre- and posttraining excitotoxic lesions of the basolateral amygdala abolish the expression of olfactory and contextual fear conditioning. Behav Neurosci. 1998;112(5):1092-103.

[21] Rosenkranz JA, Grace AA. Dopamine-mediated modulation of odour-evoked amygdala potentials during pavlovian conditioning. Nature. 2002;417(6886):282-7.

[22] Kilpatrick L, Cahill L. Modulation of memory consolidation for olfactory learning by reversible inactivation of the basolateral amygdala. Behav Neurosci. 2003;117(1): 184-8.

[23] Sevelinges Y, Gervais R, Messaoudi B, Granjon L, Mouly AM. Olfactory fear conditioning induces field potential potentiation in rat olfactory cortex and amygdala. Learn Mem. 2004;11(6):761-9. Epub 2004/11/13.

[24] Sevelinges Y, Moriceau S, Holman P, Miner C, Muzny K, Gervais R, et al. Enduring effects of infant memories: infant odor-shock conditioning attenuates amygdala activity and adult fear conditioning. Biol Psychiatry. 2007;62(10):1070-9. Epub 2007/09/11.

[25] Walker DL, Paschall GY, Davis M. Glutamate receptor antagonist infusions into the basolateral and medial amygdala reveal differential contributions to olfactory vs. context fear conditioning and expression. Learn Mem. 2005;12(2):120-9.

[26] Jones SV, Stanek-Rattiner L, Davis M, Ressler KJ. Differential regional expression of brain-derived neurotrophic factor following olfactory fear learning. Learn Mem. 2007;14(12):816-20.

[27] Sevelinges Y, Sullivan RM, Messaoudi B, Mouly AM. Neonatal odor-shock conditioning alters the neural network involved in odor fear learning at adulthood. Learn Mem. 2008;15(9):649-56. Epub 2008/09/06.

[28] Fanselow MS, Kim JJ. Acquisition of contextual Pavlovian fear conditioning is blocked by application of an NMDA receptor antagonist D,L-2-amino-5-phosphono- 
valeric acid to the basolateral amygdala. Behav Neurosci. 1994;108(1):210-2. Epub 1994/02/01.

[29] Maren S, Aharonov G, Fanselow MS. Retrograde abolition of conditional fear after excitotoxic lesions in the basolateral amygdala of rats: absence of a temporal gradient. Behav Neurosci. 1996;110(4):718-26.

[30] Miserendino MJ, Sananes CB, Melia KR, Davis M. Blocking of acquisition but not expression of conditioned fear-potentiated startle by NMDA antagonists in the amygdala. Nature. 1990;345(6277):716-8. Epub 1990/06/21.

[31] Campeau S, Miserendino MJ, Davis M. Intra-amygdala infusion of the N-methyl-Daspartate receptor antagonist AP5 blocks acquisition but not expression of fear-potentiated startle to an auditory conditioned stimulus. Behav Neurosci. 1992;106(3): 569-74. Epub 1992/06/01.

[32] Gewirtz JC, Davis M. Second-order fear conditioning prevented by blocking NMDA receptors in amygdala. Nature. 1997;388(6641):471-4. Epub 1997/07/31.

[33] Kim JJ, Lee HJ, Han JS, Packard MG. Amygdala is critical for stress-induced modulation of hippocampal long-term potentiation and learning. J Neurosci. 2001;21(14): 5222-8.

[34] Walker DL, Davis M. The role of amygdala glutamate receptors in fear learning, fearpotentiated startle, and extinction. Pharmacol Biochem Behav. 2002;71(3):379-92. Epub 2002/02/07.

[35] Goosens KA, Maren S. NMDA receptors are essential for the acquisition, but not expression, of conditional fear and associative spike firing in the lateral amygdala. Eur J Neurosci. 2004;20(2):537-48. Epub 2004/07/06.

[36] Muller J, Corodimas KP, Fridel Z, LeDoux JE. Functional inactivation of the lateral and basal nuclei of the amygdala by muscimol infusion prevents fear conditioning to an explicit conditioned stimulus and to contextual stimuli. Behav Neurosci. 1997;111(4):683-91. Epub 1997/08/01.

[37] Wilensky AE, Schafe GE, LeDoux JE. Functional inactivation of the amygdala before but not after auditory fear conditioning prevents memory formation. J Neurosci. 1999;19(24):RC48. Epub 1999/12/14.

[38] Ehrlich I, Humeau Y, Grenier F, Ciocchi S, Herry C, Luthi A. Amygdala inhibitory circuits and the control of fear memory. Neuron. 2009;62(6):757-71. Epub 2009/06/27.

[39] Stork O, Ji FY, Obata K. Reduction of extracellular GABA in the mouse amygdala during and following confrontation with a conditioned fear stimulus. Neurosci Lett. 2002;327(2):138-42. Epub 2002/07/06. 
[40] Yokoyama M, Suzuki E, Sato T, Maruta S, Watanabe S, Miyaoka H. Amygdalic levels of dopamine and serotonin rise upon exposure to conditioned fear stress without elevation of glutamate. Neurosci Lett. 2005;379(1):37-41.

[41] Young AM. Increased extracellular dopamine in nucleus accumbens in response to unconditioned and conditioned aversive stimuli: studies using $1 \mathrm{~min}$ microdialysis in rats. J Neurosci Methods. 2004;138(1-2):57-63. Epub 2004/08/25.

[42] Ungerstedt U. Microdialysis--principles and applications for studies in animals and man. J Intern Med. 1991;230(4):365-73. Epub 1991/10/01.

[43] Benveniste H, Huttemeier PC. Microdialysis--theory and application. Prog Neurobiol. 1990;35(3):195-215. Epub 1990/01/01.

[44] Parrot S, Bert L, Mouly-Badina L, Sauvinet V, Colussi-Mas J, Lambas-Senas L, et al. Microdialysis monitoring of catecholamines and excitatory amino acids in the rat and mouse brain: recent developments based on capillary electrophoresis with laser-induced fluorescence detection--a mini-review. Cell Mol Neurobiol. 2003;23(4-5): 793-804. Epub 2003/09/30.

[45] Zapata A, Chefer VI, Parrot S, Denoroy L. Detection and quantification of neurotransmitters in dialysates. Current protocols in neuroscience / editorial board, Jacqueline N Crawley [et al]. 2013;Chapter 7:Unit7 4. Epub 2013/04/06.

[46] Westerink BH. Brain microdialysis and its application for the study of animal behaviour. Behav Brain Res. 1995;70(2):103-24. Epub 1995/10/01.

[47] Watson CJ, Venton BJ, Kennedy RT. In vivo measurements of neurotransmitters by microdialysis sampling. Anal Chem. 2006;78(5):1391-9. Epub 2006/03/31.

[48] Abercrombie ED, Finlay JM. Monitoring extracellular norepinephrine in brain using in vivo microdialysis and HPLC-EC. In: Robinson TE, Justice JBJ, editors. Microdialysis in Neurosciences. Amsterdam: Elsevier; 1991. p. 253-74.

[49] Smolders I, Sarre S, Michotte Y, Ebinger G. The analysis of excitatory, inhibitory and other amino acids in rat brain microdialysates using microbore liquid chromatography. J Neurosci Methods. 1995;57(1):47-53. Epub 1995/03/01.

[50] Kehr J. Determination of gamma-aminobutyric acid in microdialysis samples by microbore column liquid chromatography and fluorescence detection. J Chromatogr B Biomed Sci Appl. 1998;708(1-2):49-54. Epub 1998/07/08.

[51] Kehr J. Determination of glutamate and aspartate in microdialysis samples by reversed-phase column liquid chromatography with fluorescence and electrochemical detection. J Chromatogr B Biomed Sci Appl. 1998;708(1-2):27-38. Epub 1998/07/08.

[52] Obrenovitch TP, Zilkha E. Microdialysis coupled to online enzymatic assays. Methods. 2001;23(1):63-71. Epub 2001/02/13. 
[53] McKenzie JA, Watson CJ, Rostand RD, German I, Witowski SR, Kennedy RT. Automated capillary liquid chromatography for simultaneous determination of neuroactive amines and amino acids. J Chromatogr A. 2002;962(1-2):105-15. Epub 2002/08/30.

[54] Lunte SM, Lunte CE. Microdialysis sampling for pharmacological studies: HPLC and CE analysis. Adv Chromatogr. 1996;36:383-432. Epub 1996/01/01.

[55] Kennedy RT, Watson CJ, Haskins WE, Powell DH, Strecker RE. In vivo neurochemical monitoring by microdialysis and capillary separations. Curr Opin Chem Biol. 2002;6(5):659-65. Epub 2002/11/05.

[56] Parrot S, Sauvinet V, Riban V, Depaulis A, Renaud B, Denoroy L. High temporal resolution for in vivo monitoring of neurotransmitters in awake epileptic rats using brain microdialysis and capillary electrophoresis with laser-induced fluorescence detection. J Neurosci Methods. 2004;140(1-2):29-38. Epub 2004/12/14.

[57] Touret M, Parrot S, Denoroy L, Belin MF, Didier-Bazes M. Glutamatergic alterations in the cortex of genetic absence epilepsy rats. BMC Neurosci. 2007;8:69. Epub $2007 / 08 / 30$.

[58] Bergquist J, Vona MJ, Stiller CO, O'Connor WT, Falkenberg T, Ekman R. Capillary electrophoresis with laser-induced fluorescence detection: a sensitive method for monitoring extracellular concentrations of amino acids in the periaqueductal grey matter. J Neurosci Methods. 1996;65(1):33-42. Epub 1996/03/01.

[59] Dawson LA, Stow JM, Palmer AM. Improved method for the measurement of glutamate and aspartate using capillary electrophoresis with laser induced fluorescence detection and its application to brain microdialysis. J Chromatogr B Biomed Sci Appl. 1997;694(2):455-60. Epub 1997/07/04.

[60] Lada MW, Vickroy TW, Kennedy RT. High temporal resolution monitoring of glutamate and aspartate in vivo using microdialysis on-line with capillary electrophoresis with laser-induced fluorescence detection. Anal Chem. 1997;69(22):4560-5. Epub 1998/01/07.

[61] Li YM, Qu Y, Vandenbussche E, Arckens L, Vandesande F. Analysis of extracellular gamma-aminobutyric acid, glutamate and aspartate in cat visual cortex by in vivo microdialysis and capillary electrophoresis-laser induced fluorescence detection. J Neurosci Methods. 2001;105(2):211-5. Epub 2001/03/29.

[62] Robert F, Bert L, Parrot S, Denoroy L, Stoppini L, Renaud B. Coupling on-line brain microdialysis, precolumn derivatization and capillary electrophoresis for routine minute sampling of O-phosphoethanolamine and excitatory amino acids. J Chromatogr A. 1998;817(1-2):195-203. Epub 1998/10/09.

[63] Tucci S, Rada P, Sepulveda MJ, Hernandez L. Glutamate measured by 6-s resolution brain microdialysis: capillary electrophoretic and laser-induced fluorescence detec- 
tion application. J Chromatogr B Biomed Sci Appl. 1997;694(2):343-9. Epub 1997/07/04.

[64] Zhou SY, Zuo H, Stobaugh JF, Lunte CE, Lunte SM. Continuous in vivo monitoring of amino acid neurotransmitters by microdialysis sampling with on-line derivatization and capillary electrophoresis separation. Anal Chem. 1995;67(3):594-9. Epub 1995/02/01.

[65] Hernandez L, Joshi N, Murzi E, Verdeguer P, Mifsud JC, Guzman N. Colinear laserinduced fluorescence detector for capillary electrophoresis. Analysis of glutamic acid in brain dialysates. J Chromatogr A. 1993;652(2):399-405. Epub 1993/10/22.

[66] Hegoburu C, Sevelinges Y, Thevenet M, Gervais R, Parrot S, Mouly AM. Differential dynamics of amino acid release in the amygdala and olfactory cortex during odor fear acquisition as revealed with simultaneous high temporal resolution microdialysis. Learn Mem. 2009;16(11):687-97. Epub 2009/10/30.

[67] Del Arco A, Segovia G, Prieto L, Mora F. Endogenous glutamate-taurine interaction in striatum and nucleus accumbens of the freely moving rat: studies during the normal process of aging. Mechanisms of ageing and development. 2001;122(4):401-14. Epub 2001/03/10.

[68] Hernandez LF, Segovia G, Mora F. Chronic treatment with a dopamine uptake blocker changes dopamine and acetylcholine but not glutamate and GABA concentrations in prefrontal cortex, striatum and nucleus accumbens of the awake rat. Neurochemistry international. 2008;52(3):457-69. Epub 2007/09/21.

[69] Layton ME, Pazdernik TL. Reactive oxidant species in piriform cortex extracellular fluid during seizures induced by systemic kainic acid in rats. Journal of molecular neuroscience : MN. 1999;13(1-2):63-8. Epub 2000/02/26.

[70] Wang CX, Erecius LF, Beverly JL, 3rd, Gietzen DW. Essential amino acids affect interstitial dopamine metabolites in the anterior piriform cortex of rats. The Journal of nutrition. 1999;129(9):1742-5. Epub 1999/08/25.

[71] Tanaka K, Graham SH, Simon RP. The role of excitatory neurotransmitters in seizure-induced neuronal injury in rats. Brain research. 1996;737(1-2):59-63. Epub 1996/10/21.

[72] Wade JV, Samson FE, Nelson SR, Pazdernik TL. Changes in extracellular amino acids during soman- and kainic acid-induced seizures. Journal of neurochemistry. 1987;49(2):645-50. Epub 1987/08/01.

[73] Bert L, Parrot S, Robert F, Desvignes C, Denoroy L, Suaud-Chagny MF, et al. In vivo temporal sequence of rat striatal glutamate, aspartate and dopamine efflux during apomorphine, nomifensine, NMDA and PDC in situ administration. Neuropharmacology. 2002;43(5):825-35. Epub 2002/10/18.

[74] Del Arco A, Mora F. Effects of endogenous glutamate on extracellular concentrations of GABA, dopamine, and dopamine metabolites in the prefrontal cortex of the freely 
moving rat: involvement of NMDA and AMPA/KA receptors. Neurochem Res. 1999;24(8):1027-35.

[75] Del Arco A, Mora F. Endogenous dopamine potentiates the effects of glutamate on extracellular GABA in the prefrontal cortex of the freely moving rat. Brain Res Bull. 2000;53(3):339-45. Epub 2000/12/13.

[76] Haberly LB, Price JL. Association and commissural fiber systems of the olfactory cortex of the rat. II. Systems originating in the olfactory peduncle. J Comp Neurol. 1978;181(4):781-807. Epub 1978/10/15.

[77] Ottersen OP. Connections of the amygdala of the rat. IV: Corticoamygdaloid and intraamygdaloid connections as studied with axonal transport of horseradish peroxidase. J Comp Neurol. 1982;205(1):30-48. Epub 1982/02/10.

[78] Luskin MB, Price JL. The laminar distribution of intracortical fibers originating in the olfactory cortex of the rat. J Comp Neurol. 1983;216(3):292-302. Epub 1983/05/20.

[79] Sah P, Faber ES, Lopez De Armentia M, Power J. The amygdaloid complex: anatomy and physiology. Physiol Rev. 2003;83(3):803-34.

[80] Haberly LB, Price JL. The axonal projection patterns of the mitral and tufted cells of the olfactory bulb in the rat. Brain research. 1977;129(1):152-7. Epub 1977/06/24.

[81] Datiche F, Cattarelli M. Reciprocal and topographic connections between the piriform and prefrontal cortices in the rat: a tracing study using the B subunit of the cholera toxin. Brain Res Bull. 1996;41(6):391-8. Epub 1996/01/01.

[82] Majak K, Ronkko S, Kemppainen S, Pitkanen A. Projections from the amygdaloid complex to the piriform cortex: A PHA-L study in the rat. J Comp Neurol. 2004;476(4):414-28.

[83] Luskin MB, Price JL. The topographic organization of associational fibers of the olfactory system in the rat, including centrifugal fibers to the olfactory bulb. J Comp Neurol. 1983;216(3):264-91. Epub 1983/05/20.

[84] Datiche F, Litaudon P, Cattarelli M. Intrinsic association fiber system of the piriform cortex: a quantitative study based on a cholera toxin B subunit tracing in the rat. J Comp Neurol. 1996;376(2):265-77. Epub 1996/12/09.

[85] Suzuki N, Bekkers JM. Inhibitory interneurons in the piriform cortex. Clin Exp Pharmacol Physiol. 2007;34(10):1064-9. Epub 2007/08/24.

[86] Benveniste H. Brain microdialysis. Journal of neurochemistry. 1989;52(6):1667-79. Epub 1989/06/01.

[87] Kanamori K, Ross BD, Kondrat RW. Glial uptake of neurotransmitter glutamate from the extracellular fluid studied in vivo by microdialysis and (13)C NMR. Journal of neurochemistry. 2002;83(3):682-95. Epub 2002/10/23. 
[88] Fonnum F. Glutamate: a neurotransmitter in mammalian brain. Journal of neurochemistry. 1984;42(1):1-11. Epub 1984/01/01.

[89] Melendez RI, Vuthiganon J, Kalivas PW. Regulation of extracellular glutamate in the prefrontal cortex: focus on the cystine glutamate exchanger and group I metabotropic glutamate receptors. J Pharmacol Exp Ther. 2005;314(1):139-47. Epub 2005/03/17.

[90] Xi ZX, Shen H, Baker DA, Kalivas PW. Inhibition of non-vesicular glutamate release by group III metabotropic glutamate receptors in the nucleus accumbens. Journal of neurochemistry. 2003;87(5):1204-12. Epub 2003/11/19.

[91] Baker DA, Xi ZX, Shen H, Swanson CJ, Kalivas PW. The origin and neuronal function of in vivo nonsynaptic glutamate. J Neurosci. 2002;22(20):9134-41. Epub 2002/10/22.

[92] Xi ZX, Ramamoorthy S, Baker DA, Shen H, Samuvel DJ, Kalivas PW. Modulation of group II metabotropic glutamate receptor signaling by chronic cocaine. J Pharmacol Exp Ther. 2002;303(2):608-15. Epub 2002/10/22.

[93] Nicholls D, Attwell D. The release and uptake of excitatory amino acids. Trends Pharmacol Sci. 1990;11(11):462-8. Epub 1990/11/01.

[94] Araque A, Li N, Doyle RT, Haydon PG. SNARE protein-dependent glutamate release from astrocytes. J Neurosci. 2000;20(2):666-73. Epub 2000/01/13.

[95] Bezzi P, Gundersen V, Galbete JL, Seifert G, Steinhauser C, Pilati E, et al. Astrocytes contain a vesicular compartment that is competent for regulated exocytosis of glutamate. Nat Neurosci. 2004;7(6):613-20. Epub 2004/05/25.

[96] Malarkey EB, Parpura V. Mechanisms of glutamate release from astrocytes. Neurochemistry international. 2008;52(1-2):142-54. Epub 2007/08/03.

[97] Timmerman W, Westerink BH. Brain microdialysis of GABA and glutamate: what does it signify? Synapse. 1997;27(3):242-61. Epub 1997/11/05.

[98] Drew KL, Pehek EA, Rasley BT, Ma YL, Green TK. Sampling glutamate and GABA with microdialysis: suggestions on how to get the dialysis membrane closer to the synapse. J Neurosci Methods. 2004;140(1-2):127-31. Epub 2004/12/14.

[99] Parrot S, Bert L, Renaud B, Denoroy L. Glutamate and aspartate do not exhibit the same changes in their extracellular concentrations in the rat striatum after N-methylD-aspartate local administration. J Neurosci Res. 2003;71(3):445-54. Epub 2003/01/15.

[100] Lada MW, Vickroy TW, Kennedy RT. Evidence for neuronal origin and metabotropic receptor-mediated regulation of extracellular glutamate and aspartate in rat striatum in vivo following electrical stimulation of the prefrontal cortex. Journal of neurochemistry. 1998;70(2):617-25. Epub 1998/02/07.

[101] Parrot S, Renaud B, Zimmer L, Denoroy L. Monitoring Neurotransmitter Amino Acids by Microdialysis: Pharmacodynamic Applications. In: Tsai T-H, editor. Appli- 
cations of Microdialysis in Pharmaceutical Science: John Wiley \& Sons, Inc.; 2011. p. 151-206.

[102] Obrenovitch TP, Urenjak J, Zilkha E, Jay TM. Excitotoxicity in neurological disorders--the glutamate paradox. Int J Dev Neurosci. 2000;18(2-3):281-7. Epub 2000/03/15.

[103] Rusakov DA, Kullmann DM. Extrasynaptic glutamate diffusion in the hippocampus: ultrastructural constraints, uptake, and receptor activation. J Neurosci. 1998;18(9): 3158-70. Epub 1998/05/09.

[104] Schousboe A, Waagepetersen HS. Glial modulation of GABAergic and glutamat ergic neurotransmission. Curr Top Med Chem. 2006;6(10):929-34. Epub 2006/06/22.

[105] Sierra-Paredes G, Sierra-Marcuno G. Extrasynaptic GABA and glutamate receptors in epilepsy. CNS Neurol Disord Drug Targets. 2007;6(4):288-300. Epub 2007/08/19.

[106] Galvan A, Kuwajima M, Smith Y. Glutamate and GABA receptors and transporters in the basal ganglia: what does their subsynaptic localization reveal about their function? Neuroscience. 2006;143(2):351-75. Epub 2006/10/25.

[107] Del Arco A, Segovia G, Fuxe K, Mora F. Changes in dialysate concentrations of glutamate and GABA in the brain: an index of volume transmission mediated actions? Journal of neurochemistry. 2003;85(1):23-33. Epub 2003/03/19.

[108] Venton BJ, Robinson TE, Kennedy RT, Maren S. Dynamic amino acid increases in the basolateral amygdala during acquisition and expression of conditioned fear. Eur J Neurosci. 2006;23(12):3391-8. Epub 2006/07/06.

[109] Denoroy L, Bert L, Parrot S, Robert F, Renaud B. Assessment of pharmacodynamic and pharmacokinetic characteristics of drugs using microdialysis sampling and capillary electrophoresis. Electrophoresis. 1998;19(16-17):2841-7. Epub 1998/12/31.

[110] Denoroy L, Renaud B, Parrot S. Capillary Electrophoresis Analysis in Neuroscience. In: He Z, editor. Capillary Electrophoresis: Fundamentals, Techniques and Applications: NOVA Science Publishers; 2012. p. 211-51. 
